\title{
Emergency remote learning during COVID-19 crisis: Students' engagement
}

\author{
Zuheir N. Khlaif $^{1} \mathbb{D} \cdot$ Soheil Salha $^{1} \cdot$ Bochra Kouraichi $^{2}$
}

Received: 19 January 2021 / Accepted: 23 April 2021 / Published online: 27 April 2021

(C) The Author(s), under exclusive licence to Springer Science+Business Media, LLC, part of Springer Nature 2021

\begin{abstract}
Student engagement in online learning enhance students performance and the outcomes of the learning process in online learning environment. The existed literature revealed various factors influencing student engagement in online leaning, however these studies were before the COVID-19 crisis. The purpose of the current paper is to explore the factors that influence student engagement in online learning during the COVID-19 crisis in middle school settings in developing countries where is a lack of studies about the factors influencing student's engagement in emergency remote learning during the crisis. A qualitative approach was used for data collection and analysis. Semi-structured interviews with 34 participants (14 students, 13 teachers, and 7 parents) were conducted for 20-30 min. Furthermore, online class observations were used for data collection; 13 online classes were observed. Each class was $40 \mathrm{~min}$. A thematic analysis was used to categorize the findings into themes and subthemes. The findings of the study revealed that various factors influence student engagement in online learning during the crisis including infrastructure factors, cultural factors, digital inequality, and the threat to digital privacy. Cultural factors were the important factor that influences females because of parents' culture and their bias against females using online learning compared to male students. Teachers' presence and quality of content were the major factors that influence student engagement, where parental concerns, norms, and traditions emerged as the major factors in the crisis, influencing engagement. Most of the participants reported that teaching and learning online during the crisis has broadened the digital inequality and threatened their digital privacy which influenced negatively student engagement. The limitations of this research included the limited number of participants covering a large geographic area, and the research design using diverse and often limited educational software and delivery methods. Future studies could utilize a mixed-method approach and include more participants.
\end{abstract}

Keywords COVID-19 • Online learning · Emergency remote teaching · ICT-based teaching $\cdot$ Remote learning

Extended author information available on the last page of the article 


\section{Introduction}

Many countries worldwide transferred education from face-to-face into remote teaching responding to the state of emergency to fight the outreach of Coronavirus (hereafter COVID-19). According to a recent report from UNESCO (2020), more than 1.9 billion students -children and youth- from 190 countries are forced to transfer their education from face-to-face to online form to fight the outbreak of COVID-19. Emergency Remote learning (ERL) is the unplanned and sudden shift from the traditional form of education into a remote one following the state of emergency in different countries due to the outbreak of COVID-19. It is different from online learning before the COVID-19 crisis in terms of course design and evaluation tools (Affouneh et al., 2020). The course design, assessment, and teaching strategies used were originally designed for face-to-face teaching. It is expected that with the end of the state of emergency, everything will go back to its nature. Moreover, educators are living under a high level of stress, anxiety, and uncertainty during the state of emergency. Indeed, faculty, students, parents, and educational institutions are not well prepared for such a situation. Emerging technologies strongly influence the learning environment in higher education settings whether using these tools on campus, blended, or fully in online environments (Czerkawski \& Lyman, 2016). These technologies reshaped student engagement for learning through new features that enable learners and instructors to communicate synchronously and asynchronously (Bergdahl et al., 2020; Khlaif \& Farid, 2018).

The shift was unplanned and sudden, which caused stress and great shock among students and instructors. Institutions have decided to switch to the online platform to provide educational services and to communicate with students through using emerging technologies. Student engagement plays a crucial role in students learning and satisfaction in distance education (Martin \& Bolliger, 2018). Different countries have used technology in online teaching for a limited time responding to crises and shutdown of schools and universities (Czerniewicz et al., 2019; Khlaif \& Salha, 2020; Khlaif et al. 2021). In this transition, new technological tools were used for the first time by both learners and teachers.

\subsection{Context of the study}

The context of the study was middle school settings in Palestine which is a developing country. Middle school started from 5th to 9th grade. The emergency remote teaching procedure was introduced by the Ministry of Education (hereafter MoE) in Palestine for all public and private schools on all levels based on the government declaration of the emergency state to fight the outbreak of COVID-19 without stating any deadline to the end of the emergency state. The MoE decided to continue teaching online until the end of the age of COVID-19. All the teachers were trained to use open sources and different platforms to support their students including Google Classroom, Microsoft Teams, H5P, and Zoom. Teachers were using synchronous, asynchronous, and blended one (synchronous and asynchronous) to provide students with online activities. Teachers 
monitored student's engagement in the synchronous and asynchronous by electronic form for attendance, implementing the online activities, participating in the online discussion, assessing the students' tasks. Both teachers and students have had access to MS Teams and provided a free account from the MoE as well as the Zoom platform. Some schools used the free account on the Google classroom platform.

\subsection{Rationale of the study}

There has been an abundance of research on online learning before the COVID-19 crisis to understand the factors influencing student's engagement in online learning which could differ from the factors influencing student's engagement in online learning during a crisis like the COVID-19 pandemic. Teachers, students, and parents were shocked and have a lot of stress because of the transition to online education suddenly and without any preparation which could influence the level of engagement in the new online learning environment (Khlaif et al., 2020).

Building on the premise that engagement is essential for learning in online environments in higher education, recent research has begun to explore student engagement in middle school settings in the normal situation before COVID-19 (Cipriano et al., 2019). However, previous studies had explored factors that influence student engagement in online learning environments before COVID-19 The motivation of the present study is to explore the factors that influence student engagement during the COVID-19 crisis. Moreover, most of the previous studies were conducted in western countries; however, the present research sheds light on developing countries, where Palestine is a case study of the developing countries. The finding of the current study, which was conducted in Palestine with its unique case where people are living under crisis, could inspire decision-makers in the Middle-East area, especially the countries that are suffering from the unstable and violent situation in addition to the COVID-19 crisis. Therefore, the purpose of this study was to explore the factors influencing student engagement in the middle school settings in emergency remote teaching (ERL) during the COVID-19 crisis from the viewpoints of teachers, parents, and students. Consequently, the following two research questions drove the current study:

- What are the factors that influence student engagement in the emergency remote learning environment with COVID-19 in developing countries?

- How do these factors influence the implementation and continuity of online classes in an emergency remote environment in developing countries?

\section{Literature review}

\subsection{Definition of student's engagement}

Different definitions of student engagement have been proposed by many researchers. For example, Bond (2020) defines engagement as "the energy and effort that students employ within their learning community, observable via any 
number of behavioural, cognitive or affective indicators across a continuum" (p. 3). In addition, Dixson (2015) defines it as the effort that the learner makes to acquire knowledge and build his/her critical thinking skills through staying involved in the learning process. Moreover, Wong and Chong (2018) defined online engagement as a unique collection of comprised active and collaborative learning, participation in enriching learning activities, communication with teachers and among learners, involvement in educational experiences, and feeling supported.

Martin and Bolliger (2018) state that engagement and interaction are used interchangeably and closely and stated three types of engagement including learner-tolearner engagement, learner-content engagement, and learner-instructor engagement. Furthermore, in their study, Khlaif and Farid (2018) put forward three types of interaction in online discussion forums including one-way, two-ways, and complex interaction. Based on the previous definition of student's engagement, we viewed student engagement as attending online sessions (synchronously and asynchronously), communicating with peers and the instructor, participating in the online class activities, being a knowledge producer (recording a short video to explain an idea, designing a PowerPoint presentation) and the efforts that students make in their learning environment.

\subsection{Importance of student's engagement}

Educators seek to use the best strategies to enhance student engagement in an online environment during the COVID-19 crisis. Student engagement refers to students' level of involvement with and effort in learning (Wang et al., 2019), which would enhance students' academic achievement (Alrashidi et al., 2016). Other researchers regarded that student engagement may improve retention, performance, and persistence (Bergdahl et al., 2020; Bond, 2020). Student's engagement and participation are recognized as important impacts on learning and performance, especially in online learning. The findings of previous studies stress the importance of engagement to mitigate the rate of dropout, students' isolation in the online environment, and retention (Ansong et al., 2017; Martin et al., 2018). Anderson (2017) mentioned learners' engagement and its influence on learning is a very challenging factor in learning performance and it should be measured due to the available data of the online learning environment. Tao et al. (2018) found accomplishment, learning joyfully and level of effort are dominant factors in students' engagements in online learning environment. Fraysier et al. (2020) reported that student engagement is a significant factor in decreasing school dropout and improving student achievement. Moreover, Tualaulelei et al. (2021) introduced students' engagement as a motive of their potential and to maximize their learning opportunities. Banos et al. (2019) linked student engagement with several factors as their participation in extracurricular activities, social activities, and time with close group. 


\subsection{Factors influencing students' engagement in online learning}

\subsubsection{Social support}

Social support which is from teachers, parents, and peers have been emerged as an important factor that positively influenced students' engagement (Ansong et al., 2017). Another study conducted by Nortvig et al. (2018) reported that teacher's presence in the online learning environment, interactivity between students with their peers, with teachers, and the content, and the connection in the activities between offline and online activities have a positive impact on students' engagement in the online learning environment. Czerkawski and Lyman (2016) claimed teachers and principals' support is a significant factor in learners' engagement in an online environment. Wang and Sui (2020) concluded students' emotional and cognitive engagement are correlated to self-regulated learning, they advised instructors to engage students emotionally in order to succeed in online learning. Moreover, Liu and Zhang (2020) reported that social interaction among learner to learner and teacher to learner contribute to significant students' engagement in the online learning environment. While Oliveras-Ortiz et al. (2020) concluded that the characteristics of learning environments as design and spaces affect students learning and engagement. Hammill et al. (2020) proved that positive psychology and mindfulness interventions enhanced student engagement.

\subsubsection{Design of online content and activities}

Previous research revealed that the desired high-quality content is well-organized activities with well-specified learning objectives (Chen et al., 2018); they are also expected to be useful and easy to use in online learning activities (Keržič et al., 2019). Moreover, the design of the online learning environment plays an important role in student engagement (Al Mamun et al., 2020; Zydney et al., 2020) which includes Learning Management System (LMS) and digital content. LMS contains different tools including collaboration tools to enhance opportunities for building a community of learners, sharing knowledge, enhancing critical thinking, and supporting higher-order learning through collaboration and conversation (Zanjani, 2017). Lee and Hannafin (2016) found that well-defined and organized activities with various types of learning resources enhance student engagement in the learning process. In addition, Liu and Zhang (2020) showed various online content types such as activities and arguments contribute to students' engagement. Wong and Chong (2018) added immediacy, frequency, and duration key factors in online engagement and its level. Bovermann and Bastiaens (2020) presented gamification and games as efficient tools and activities to engage students during online learning.

\subsubsection{Student self-efficacy}

Computer self-efficacy of the students influences student's engagement in online learning as well as student's attitudes towards online learning (Pellas, 2014). Students' beliefs and attitudes towards online learning play crucial role in students' 
engagement (Tofel-Grehl et al., 2017). In a recent study about the factors that influence student's engagement in emergency remote teaching during the crisis in Indonesia, Lie et al. (2020) found that previous experience with technology, technological knowledge, pedagogical knowledge, and the support system play an important role to enhance student engagement in online learning. We developed a diagram (Fig. 1) to represent the factors influencing student engagement as reported in the literature review.

We noticed from the previous studies that these studies were conducted in a different context from the current study and conducted in an environment before the COVID-19 crisis which could the factors influencing student engagement differ from the factors that would emerge and affects engagement in the ERL during crisis.

\section{Methodology}

\subsection{Research design}

In response to the purpose of the study to explore the factors influencing student engagement in online learning during the crisis, we used a case study design and collected qualitative data from different teachers who were teaching in online learning during the COVID-19 crisis in different middle school settings located in different places in Palestine. A descriptive case study was used to describe an intervention or phenomenon in a real-life context in which it occurred (Yin, 2014). The phenomenon in the current study was the mandatory moving from face-to-face learning to emergency remote learning in a short time without any preparation. The study was carried out after eight months of implementing the emergency remote teaching in Palestine which was already suffering from violence and unstable situation even before the COVID-19 pandemic.

Fig. 1 The relationships between the themes and subthemes with student engagement as reported by the participants

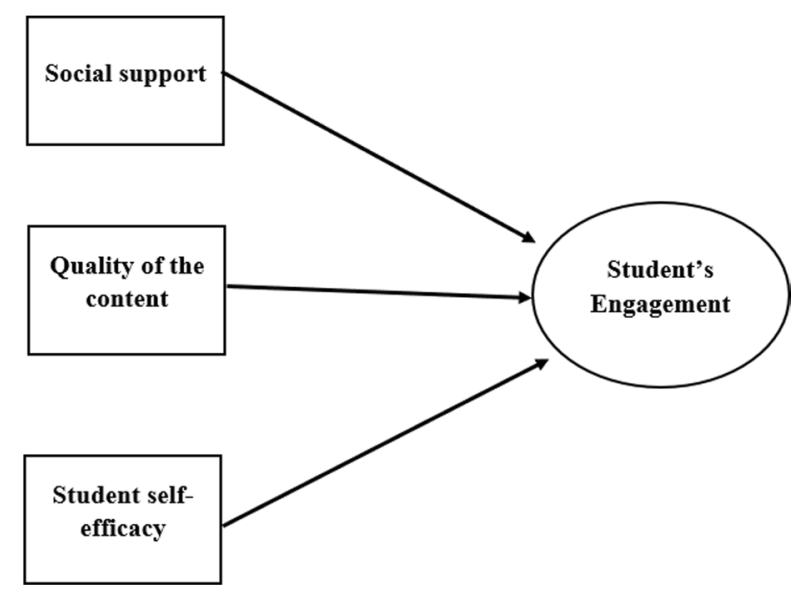




\subsection{Choosing schools and the participants}

The researchers contacted the educational technology department, the supervisor, and the teacher-training department in the Ministry of Education to nominate schools to participate in this study based on the following criteria: schools that are located in an underprivileged area; schools that have initiatives to use technology in education before COVID-19 crisis; middle schools (grades 5-9); different types of schools (all-boys, all-girls, and mixed schools); as well as schools that started to teach online in the COVID-19 crisis. The Ministry of Education nominated 15 schools from different districts. The researchers sent an invitation letter to the 15 schools providing information about the study and its goals. Three schools out of 15 agreed to participate in the study. Another invitation letter was sent to the teachers in the three schools to participate in the study. The selection criteria for teachers were having taught online before and during COVID-19; living in a marginalized area; accepting to observe his/her online classes (synchronously); agreeing to invite the researchers to observe his/her asynchronous online classes over Google Classroom, and teaching middle-school grades (5-9). Most of the participants of the study used open sources and free platforms to design their online activities. The digital activities were delivered on Teams, Zoom, and Google Classroom.

\subsection{Participants}

Thirty-four participants from middle schools located in different locations in Palestine (13 teachers, 14 students, and 7 parents). Teachers and students were from three schools including one of the schools was an all-boys school (three teachers, five students, and two parents), another one was a mixed school (two male teachers, three female teachers, three male students, four female males, three female parents), and the last one was an all-girls school (five female teachers, two female students, and two female parents). At the time of the study, teachers were teaching different topics for middle school students which range from 5th to 9th grade. To recruit parents, an invitation was sent to parents to participate in the study. The invitation was sent with their children in the participated schools. Table 1 provides an overview of gender and the number of participants from each school.

\subsection{Ethical clearances.}

The researchers got permission from the MoE and approval to conduct the research in the public school from the Directorate of Scientific Research and Development. In addition, the researchers obtained parents' consent to allow their children to participate in the study. The principals of the schools and the teachers gave their agreement to the researchers to observe their online classes. 
Table 1 Gender and number of the participants from each school

\begin{tabular}{|c|c|c|c|c|c|c|c|}
\hline \multirow[t]{2}{*}{ School } & \multirow[t]{2}{*}{ School Type } & \multicolumn{2}{|c|}{ Teachers } & \multicolumn{2}{|c|}{ Students } & \multicolumn{2}{|c|}{ Parents } \\
\hline & & Male & Female & Male & Female & Male & Female \\
\hline School 1 & Boys & 3 & 0 & 5 & 0 & 2 & 0 \\
\hline School 2 & Mixed school & 2 & 3 & 3 & 4 & 0 & 3 \\
\hline School 3 & Girls & 0 & 5 & 0 & 2 & 0 & 2 \\
\hline Total & & 5 & 8 & 8 & 6 & 2 & 5 \\
\hline
\end{tabular}

\subsection{Data collection}

\subsubsection{Semi-structured interviews}

Semi-structured interviews were the major data collection method. An interview protocol (Appendix A) was developed in the Arabic language for the participants to inform the participants about the purpose of the study and why we choose them to participate in the study, to get their consent to record the interview, and the procedures of the interview. The researchers asked the participants about their experience with emergency remote learning. In addition, the researchers asked teachers about the differences between emergency remote learning (ERL) during COVID-19 and their teaching and learning online before COVID-19, the challenges they faced in the ERL environment, and how teachers encourage students to engage in the online activities. Individual interviews were also conducted via Zoom for 20-30 min. A consent form was signed beforehand by each participant to record the interview.

An interview protocol (Appendix B) was developed to conducted individual semi-structured interviews with parents (two males and five females) for $30 \mathrm{~min}$ through Zoom. The interview questions were about their satisfaction with their children learning in online learning environment through talking about their experience with their children in the new learning platform. In addition, we asked them about their concerns while their children are learning in online environment.

Semi-structured interviews based on the interview protocol (Appendix C) were conducted with 14 students from different schools for $30 \mathrm{~min}$ by using Zoom. Before the interview, we obtained parental consent to interview students. The interview questions focused on students experience with online learning during the crisis, their concerns, challenges, and participating in the online activities.

\subsubsection{Online classroom observation}

The researchers developed an observation protocol (Appendix D) to observation online sessions to measure how students engage in online activities and how teachers encourage students to engage in online activities and discussions. The development of the online classroom observation was based on different previous studies including Wheeler et al. (2019) and Topçu et al. (2018) studies. The first two 
researchers observed 13 online classes for $40 \mathrm{~min}$ each. Around $8 \mathrm{~h}$ of online classes were observed. The researchers wrote their notes about online class procedures, type of content, instructional issues, technical issues, student engagement in the discussion and the activities, how teachers encourage students to participate in the online activities, and how teachers monitored student engagement.

\subsection{Data analysis}

The data analysis process started by transcribing the interviews manually. The data were analysed by using inductive thematic analysis (Braun \& Clarke, 2006). The first two authors individually read each transcript and divide it into small units based on the concepts and ideas. Line numbers were added for each text idea. The main idea of each unit was identified. Similar ideas and concepts were grouped into a theme and named it based on the findings of previous studies. Themes were developed based on the main ideas in the small units (Cresswell, 2012). Related themes were categorized and organized in clusters. A codebook was developed based on the discussion between the researchers. Table 2 introduces an example on inductive thematic analysis.

After constructing the themes and subthemes that emerged in the analysis of interviews, the researchers used these themes to analyse the online class observation data. The ideas and concepts reported in the observation form were organized within the themes and subthemes that emerged from the interview's analysis. New emerging themes that were not present in the interview analysis were reported. For example, we noticed that teachers did not design activities for students with a disability which we considered it as an emerging subtheme in the digital inequality. Furthermore, in mixed classes (male and female students), teachers were biased with male students more than females through asking male students more questions than females. The final themes and subthemes are summarized in Tables 3 and 4.

\subsubsection{Trustworthiness}

After the end of the interview transcriptions, the researchers sent the transcripts to participants for member checking, asking to verify the content for accuracy. Moreover, participants were asked to write notes, rewrite, and add new information to the transcripts. No one added or altered the original statements. With the final themes constructed, two professors in educational technology were asked to take $10 \%$ of the transcription and analyze it based on the constructed themes to check the accuracy of the themes.

\section{Results}

The researchers found an important variant between the three types of participants (teachers, students, and parents) in terms of the factors that influence student's engagement which was the cultural factors that affected student's engagement in the 


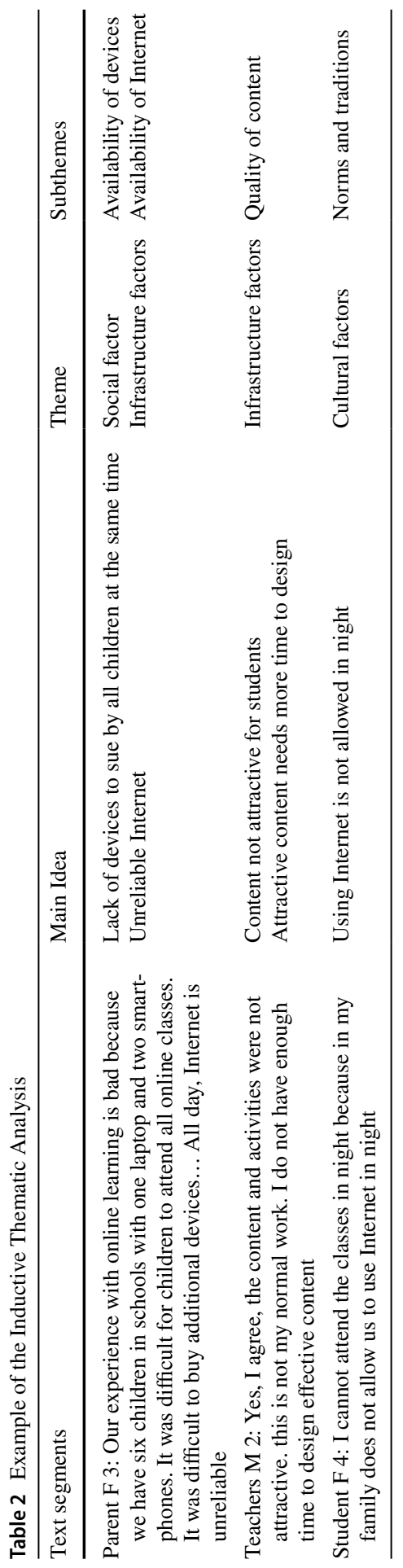




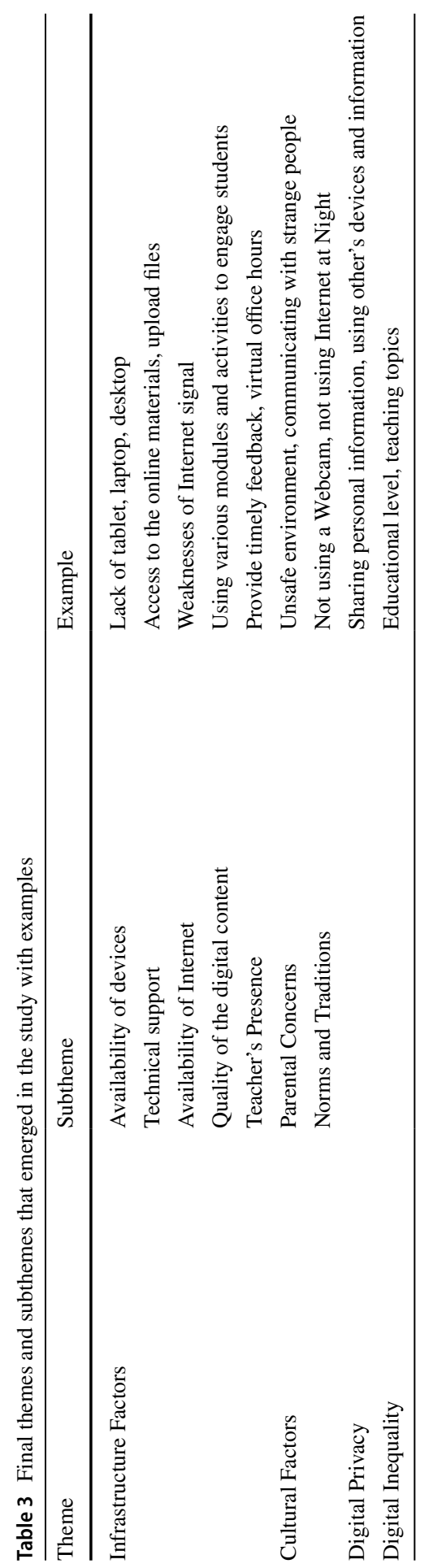


Table 4 Summary of the dimensions of the digital inequality due to EML during COVID-19

\begin{tabular}{|c|c|}
\hline Digital inequality in & Example \\
\hline Infrastructure & $\begin{array}{l}\text { "I missed four classes because at the class time } \\
\text { there was no electricity. How will I be able to } \\
\text { attend and engage in online learning?" (Student } \\
\text { M 3) }\end{array}$ \\
\hline $\begin{array}{l}\text { Meaningful, high-quality, culturally appropriate } \\
\text { content }\end{array}$ & $\begin{array}{l}\text { "Designing and sharing high quality was difficult } \\
\text { because it was an unplanned and sudden move to } \\
\text { ERL" (Teachers M 5) }\end{array}$ \\
\hline Lack of computer-friendly teacher & $\begin{array}{l}\text { "I am not prepared to use technology in online } \\
\text { learning for the whole class and for a long time" } \\
\text { (Teacher F 4) }\end{array}$ \\
\hline $\begin{array}{l}\text { Parents' inability to follow their children in the new } \\
\text { model of education }\end{array}$ & $\begin{array}{l}\text { "I have five kids, each one has at least five assign- } \\
\text { ments per week, it is difficult to follow them and } \\
\text { I am not qualified to use new technology' (Parent } \\
\text { F 5) }\end{array}$ \\
\hline Educational levels & Online classes focused on middle schools \\
\hline Students with disability & $\begin{array}{l}\text { Teachers did not design suitable content for these } \\
\text { important students in the community }\end{array}$ \\
\hline Focusing on specific branches of middle school & $\begin{array}{l}\text { Teachers reported they focused on scientific stream } \\
\text { and ignoring grades } 1-4\end{array}$ \\
\hline submitting "articles" topics & $\begin{array}{l}\text { focusing on scientific subjects and sometimes on } \\
\text { languages }\end{array}$ \\
\hline Internet broadband Connectivity & $\begin{array}{l}\text { "It is difficult to upload the file of the assignment } \\
\text { because of the limited Internet connection" (Vari- } \\
\text { ous students males and females) }\end{array}$ \\
\hline
\end{tabular}

ERL environment which was raised by many parents. However, the researchers will come back to this factor while presenting the findings in the following paragraphs.

\subsection{The factors that influence student engagement in the emergency remote learning environment with COVID-19}

Based on the thematic analysis of the data from the semi-structured interviews and the online class observation, participants identified four factors that they believe influenced student engagement in emergency remote learning during COVID-19. All participants reported that these factors should be considered to continue online learning during COVID-19. These key factors were cultural, infrastructure, digital equity, and digital privacy. Table 3 represents the final themes and subthemes that emerged in the present study.

\subsection{Cultural factors}

Cultural factors, which included parental concerns related to religious issues as well as norms and traditions, played an important role in student engagement as reported 
by most of the participants in this study. Most of students raised many concerns about the time of the online activities and the group-work.

\subsubsection{Parental concerns}

Parents raised important issues about safety in an online learning environment since they do not have the skills to protect their children on the Internet and to educate them about their safety in the forced online environment. One parent said: "I do not have the necessary skills, nor does my husband, to protect our girls and I don't like how students are forced to study online without any preparation" (Parent F6).

Another parental concern was about using webcam in online learning due to religious beliefs and local culture. A father said, "I do not want my girl to use the webcam in online learning, my religious beliefs not allowed males and females to communicate with another gender, also I do not know who is on the web, I do not know the application they are using for online learning" (Parent M7).

\subsubsection{Norms and traditions}

Another cultural factor reported by students and parents that negatively influenced student engagement in online learning during COVID-19 was the local traditions and norms of the family. Some families did not allow their children to use the Internet, especially teenagers due to their culture as well as religious beliefs reported by three parent females. Furthermore, some students reported that their families allowed them to use the Internet for a limited time which could make them miss some online sessions.

Usually, my dad allows us to surf the Internet for one hour in the afternoon, at that time we do not have online classes, I tried to change my turn to connect to the Internet, but my older brother has classes. (Student F6)

Teachers in the interviews complained about some students who did not attend their classes because the time was in the evening and parents preferred morning classes.

Additionally, female students reported that they cannot use the Internet until their dad came back home in the evening. For example, one female student stated that she cannot use Internet unless one of her parents is at home. Another female said she can only access the Internet when her dad is at home because the Internet is only available on his Phone (Student F7).

\subsection{Infrastructure factors}

All participants expressed the importance of the learning environment for student engagement in emergency remote learning. Participants were asked about the characteristics of the learning environment. The answer was that it was the students' and teachers' home. Most of them mentioned that they know the learning environment as their school, but in this situation [emergency remote learning] the environment is 
their place, which is new for them. A question was asked to the participants about their definition of the learning environment. All participants described their home environment including the availability of devices, technical support and Internet, and the learning space.

A female teacher stated: "[t]he learning environment is my placement...the room where I am setting it to be suitable for teaching online...I need to put all the teaching tools in this room including laptop, Webcam, internet" (Teacher F3). Another male teacher said: "...Usually, I do not allow my kids to enter my room while I am presenting for my students...You know this puts more stress on the family" (Teacher M2).

Different subthemes have been reported by the participants related to the infrastructure factors including availability of technological devices, technical support, Internet access, quality of the digital content, and teachers' presence.

\subsubsection{Availability of technological devices}

Availability of the technological devices such as desktop computers, laptops, smartphones, and tablets is important for students to attend the online session and to participate in asynchronous and synchronous learning activities as reported by all participants. A follow-up question was sent to the parents about whether they do not have devices or there is a shortage of devices. All mentioned that they have devices, but these devices are not sufficient for their kids. One said "I have five kids and we have only two smartphones... These devices are not sufficient to do the assignment or to attend synchronous sessions...Most of the classes were at the same time... Because of the crisis [COVID-19] all my kids have to learn online. It is miserable for us" (Parent F1). One student said: "it is difficult for me to do the assignment by using iPhone...The teacher asked me to write a report about two pages, we do not have a laptop or a desktop, only a smartphone" (Student M2).

Based on data analysis, lack and availability of devices, as well as the type of these devices, have a negative effect on student engagement in emergency remote learning during COVID-19 because most of the Palestinian families have many children at schools.

\subsubsection{Technical support}

Most of the participants reported that they faced many technical challenges while trying to access Google classroom or to attend the synchronous sessions which prevented them from continuing online learning with their peers. They reported that they cannot get any support from teachers or school administration because of quarantine in the COVID-19 crisis. Furthermore, many teachers mentioned that they have many challenges to upload the learning materials on Google Classroom and did not find anyone to help them, because they were unqualified and lack the skills to use it. A teacher said: "I am not qualified to solve technical support in using Google 
classroom, it is even difficult to ask colleagues to help you due to the crisis [COVID19]" (Student M9; Teacher M5).

\subsubsection{The weakness of Internet}

Many participants complained about the weakness of the Internet signal which prevented them from attending synchronous sessions and communicating with their peers and teachers. Teachers asserted that they sometimes cannot upload the activities and presentation files on Google classroom because of the limited Internet connection. One female said: "I failed many times to upload a file or an activity to the students because of the weak Internet connection" (Teacher F4).

Some students complained about the quality of the synchronous online session because of Internet. "Sometimes it is difficult to understand what the teacher said because of Internet disconnection and the disruption in the teacher's voice because many people are using Internet in Coronavirus" (Student M5). A strong Internet connection is important for students, teachers, and parents important to communicate and learn online during COVID-19.

\subsubsection{Quality of the digital content}

Teachers and students reported that the quality of the content in the ERL was lower than that in face-to-face and normal online learning. The teachers' justification was that they do not have time to design high-quality content for their classes. One female said: "We moved suddenly to online learning and it [course design] needs more time to design the activities and evaluation tools" (Teacher F6).

Moreover, some teachers mentioned that the weak Internet signal affected the quality of the content as well as the quality of the audio files. "[The Internet signal plays important role in the quality of the audio as well as the video I presented in online classes" (Teachers M8).

\subsubsection{Teacher's presence}

Students and parents asserted that the teacher's presence in online courses is important for scaffolding, facilitating learning, reducing distance in learning, providing more instruction about the assignments and activities, and engaging students in online learning during COVID-19. One teacher said: "the teacher is important in online learning...He/she can mitigate the difficulties students have, answer their questions, and reduce the isolation of students in online learning in this crisis [COVID-19]" (Parent M 5). All students and parents agreed with this statement. A follow-up question was about the teacher's presence. The answer was that teachers can establish different tools for communication, can add some comments to encourage students as well as making a short weekly meeting via Zoom. 


\subsection{Digital privacy}

All the participants reported that their digital privacy was threatened while learning in the emergency remote learning environment. Parents reported that sharing devices such as smartphones, laptops, or desktops are considered as breaching individual privacy. Few (female) students reported that their teachers asked them to open a Webcam which they considered as an invasion of their digital privacy. These females informed their parents about the matter. Other parents reported that they did not allow their daughters to attend online classes because the teacher asked them to share personal information such as their social media account and to share their laptop screen.

A few students reported that they hesitate to attend and participate in online learning due to the harm of their digital privacy. Some teachers confirmed that they asked their students to open the Webcam during a presentation or when they ask questions. All the parents in the study reported that their digital privacy was threatened when they share their devices with their children because all their children have different classes at the same time. Breach of students' and parents' digital privacy has increased in the emergency remote teaching during the coronavirus pandemic which reduced student engagement in online classes.

\subsection{Digital inequality}

Shifting to emergency remote education suddenly in COVID-19 deepened the digital inequality as reported by the participant in the study which reduced student engagement in online learning and attending synchronous learning sessions. One female said, "we are forced to use it [online learning] because of the virus, we were not ready in the family for this" (Student F5). A parent said, "I cannot buy more devices because I have lost my job due to Corona" (Parent M8).

A female student said, "I cannot attend synchronous classes because, at the class time, my sister is using the device [Laptop]" (Student F2). Another female student mentioned that "before this crisis, I used to use my mom's iPhone to finish my assignments, but now I cannot because she uses it to teach her students" (Student F4).

It seems that COVID-19 broadened the digital divide among students as it forced them to switch into emergency remote education suddenly and without preparation for all students at all levels. All students reported that inequality in the new learning paradigm mitigates their engagement in online courses. The digital inequity dimension due to the emergency remote learning during COVID-19, as reported by the participants and observed in the online classes, were summarized in Table 3 based on the dimensions of Resta's et al. (2018).

All the participants reported that they suffered from digital inequality while teaching and learning remotely in the state of emergency which put them under high pressure and anxiety because they do not know when this emergency state will finish going back to the normal form of learning. 


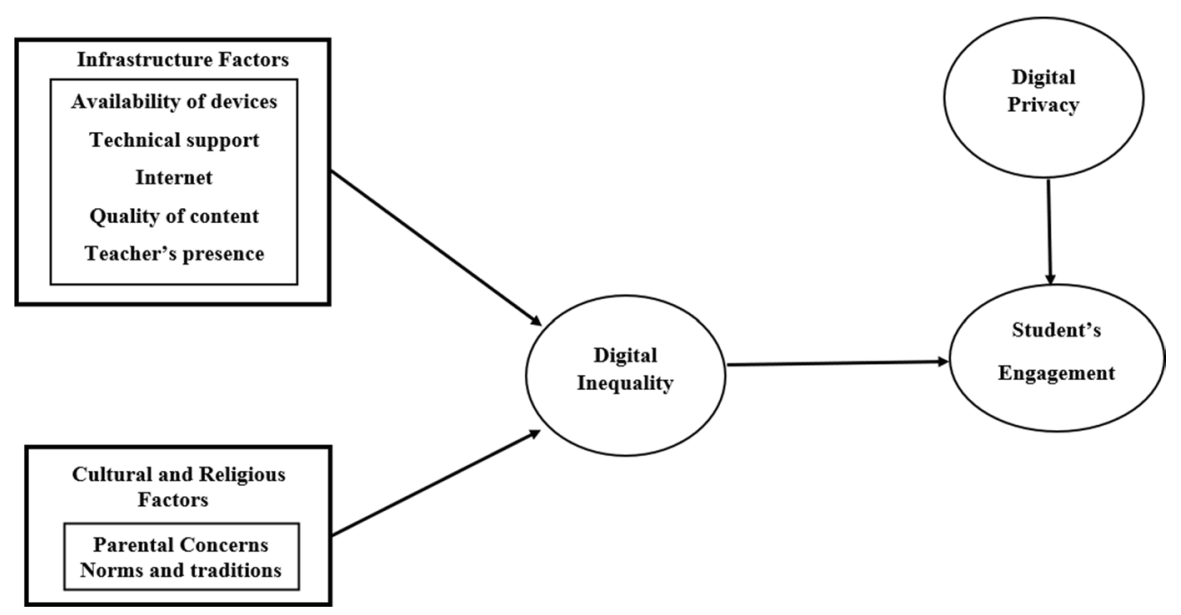

Fig. 2 The relationshipsbetween the themes and subthemes with student engagement as reported by theparticipants

The participants reported that infrastructure and cultural factors have an influence on the digital inequality they faced which affects their digital privacy. The researchers illustrate the relationship between these factors and digital inequality, the digital privacy, and student engagement as reported by the participants in Fig. 2.

\subsection{The effect of the factors on emergency remote learning}

Emergency remote learning during COVID-19 was completely different from normal online learning as reported by both teachers and students. Teachers reported that the unplanned situation put them under stress because they were unprepared to teach online. Many of the teachers reported that instruction from the Ministry of Education was unclear.

Also, teachers reported that they did not have enough time to design high quality content and activities for their students by following the instructional design process and principles. A female teacher reported that "we moved suddenly to online teaching...no time to design high-quality content suitable for students" (Teacher F13). Another male teacher said, "I need more time to design good content for all my students...I attended training to design content for all students, but it needs a lot of time because you need to prepare and to plan to design this kind of content which is not available in this emergency situation" (Teacher M 8).

Students reported that their engagement in online courses influenced negatively in ERL during COVID-19 due to the digital inequality which was influenced by the characteristics of the learning environment and put their digital privacy at risk 
due to digital inequality. Many (female) students reported that digital equality is important for them to engage in online learning activities.

\section{Discussion}

The finding of the current study, which was conducted in Palestine with its unique case where people are living under crisis, could inspire decision-makers in the Middle-East area, especially the countries that are suffering from unstable and violent situation in addition to the COVID-19 crisis. This combination of factors, the usual daily stress in society and the additional restrictions from the pandemic, makes this case study a particularly challenging scenario to provide quality education under the current terms. The transition from classroom learning to online learning caused major shock and discomfort to all the educational process stakeholders from the learning center team to students and parents. Through exploring the factors that influence student engagement in emergency remote learning in COVID-19 in middle school settings in Palestine, emerging factors have emerged. These factors include cultural factors, namely parental concerns which related to religious issues as well as local culture and norms and traditions that have negatively influenced student engagement in online learning during the COVID-19 crisis. Cultural factors were related to the student's environment and their parent's beliefs in religion who did not allow their children to attend online learning sessions at the night and not allowing them to open the web camera, especially the females. The findings of this study congrue with the findings of Ansong et al. (2017) study which also considers digital inequality and bias against females. They also investigated digital inequality among students. Those from a conservative family did not have an equal chance to enjoy online learning. In addition, some parents were concerned about digital privacy. They considered online learning as a threat to their child's digital space.

The participants of the study considered the socioeconomic factors as crucial factors for student engagement, specifically teacher's presence and connectedness in the ERL environment since teachers can facilitate learning and provide comments and feedback on students' responses as well as scaffolding students to finish tasks during the online course. Despite the context of the current study as well as the characteristics of it, the findings of this study support the findings of previous studies in terms of the importance of teachers' presence to enhance student engagement. Many previous studies confirmed the role of teachers' presence in an online environment (synchronous and asynchronous) such as Dwivedi et al. (2019) study and Martin et al. (2018).

Moreover, the findings confirm that the quality of the digital content was important for student engagement as reported by the participants. They support the findings of Dwivedi et al. (2019) and He et al. (2019), and Arghode et al. (2018). Due to the lack of time and unplanned transformation to ERL, the quality of the courses was low, which increase the gap between the ERL courses compared with the normal online courses Affouneh et al. (2020). Following the 
instructional design principles is important to have high quality of electronic content to be used in ERL. Other infrastructure factors including the availability of devices, internet connection, and technical support were important factors since the learning environment changes from schools to students' and teachers' homes, which is different from the official environment. These issues can be solved through supporting of the private sectors, non-profit organizations, and the Ministry of Education.

All the infrastructure factors have a negative effect on the digital inequality in ERL because of the COVID-19 pandemic. Therefore, the findings of the current study revealed that COVID-19 widened the digital inequality in the learning community. It also influenced student engagement in online learning. These findings partially support previous studies such as He et al. (2019) and Martin et al. (2018). Infrastructure factors, which always is, no matter pandemic, lockdown or any other situation of stress. Infrastructure including devices, suitable content, Internet, and technical support becomes a significant pillar of education as a support to store resources, give online classes, share content, encourage contribution, and other actions. Without a powerful, diverse and properly distributed technological layer, engaging teachers and students into online settings become unlikely. Infrastructure must work properly and timely so that the target groups can focus on methodology and content, using that very tool as a means.

The findings of the study revealed different dimensions about the digital inequality that happened in online learning during COVID-19 which are compatible with the findings of Resta et al. (2018), Traxler et al. (2019), and Affouneh et al. (2020). Indeed, the internet was not accessible for many students, and it varied in quality and speed for others. Furthermore, the participants reported that digital inequality was influenced by infrastructure and cultural factors.

In fact, the findings of this study highlighted many challenges associated with emergency remote teaching. These challenges were related to the learning environment of both students and teachers, the quality of the digital content, digital inequality, and concerns over digital privacy. The last factor reported by the participants that influenced student engagement is digital privacy such as hacking the accounts of their children as teachers used free platforms in ERL. This assumption in line with Ahmed and Booth's (2016) study and Robertson's et al. (2019) study.

The results of the present study have shown that student engagement in ERL during the COVID-19 was affected by interrelated factors. It should be noted that some factors such as the quality of the online materials are due to the sudden change to online instruction which is not allowed to follow instructional design process to prepare interactive content and activities. However, other factors such as the cultural factors and the threat of one's digital privacy will still remain in place after the crisis. This study has actually brought to the surface some issues that should be studied were we to consider a permanent switch to online learning in the long run. More to the point, Palestinian teachers and curriculum designers should consider these factors and try to solve some of the problems if the crisis takes longer. 


\subsection{Limitation of the study and future research}

The limitations of this research included the limited number of the participants covering a large geographic area, and the research design using diverse and often limited educational software and delivery methods. Conducting a large-scale study could reveal more information about the topic under investigation. Future studies could utilize a mixed-method approach and include more participants.

\section{Conclusion}

The purpose of this study was to explore the factors that influence student engagement in emergency remote teaching in COVID-19 in Palestine. Based on the findings reported by the participants, it seems that the COVID-19 crisis negatively influenced student engagement in emergency remote learning because of the emerging new challenges during the learning process. The challenges were infrastructure factors, cultural factors, digital inequality, and digital privacy. Furthermore, the digital inequality was influenced by many factors such as infrastructure and cultural factors. Breach of digital privacy issues negatively influenced student engagement in the ERL environment.

Generally speaking, the level of student engagement in ERL environment was not the same as that before the COVID-19 crisis. Moreover, the quality of the digital content was low compared to the content for online learning under normal circumstances. It is crucial to say that COVID-19 raised up the necessity to achieve the digital equality and privacy even in simple requirements. It was obvious that the absence of the concept and processes concerning instructional design among teachers in ERL settings deepened the digital inequality and threatened digital privacy.

Supplementary Information The online version contains supplementary material available at https://doi. org/10.1007/s10639-021-10566-4.

\section{Declarations}

Conflict of interest No conflict of interest.

\section{References}

Affouneh, S., Salha, S., \& Khlaif, Z. N. (2020). Designing quality e-learning environments for emergency remote teaching in coronavirus crisis. Interdisciplinary Journal of Virtual Learning in Medical Sciences, 11(2), 135-137.

Ahmed, A. \& Booth, D. (2016). The Digital Privacy Laws and Practices in the Jersey Island. Procedia Computer Science, 163 -168. https://doi.org/10.1016/j.procs.2016.09.026

Al Mamun, M. A., Lawrie, G., \& Wright, T. (2020). Instructional design of scaffolded online learning modules for self-directed and inquiry-based learning environments. Computers \& Education, 144, 103695 . 
Anderson, E. (2017). Measurement of online student engagement: Utilization of continuous online student behaviors as items in a partial credit rasch model (Doctoral dissertation). Retrieved from https://digitalcommons.du.edu/etd/1248

Ansong, D., Okumu, M., Bowen, G. L., Walker, A. M., \& Eisensmith, S. R. (2017). The role of parent, classmate, and teacher support in student engagement: Evidence from Ghana. International Journal of Educational Development, 54, 51-58.

Arghode, V., Brieger, E., \& Wang, J. (2018). Engaging instructional design and instructor role in online learning environment. European Journal of Training and Development.

Alrashidi, O., Phan, H. P., \& Ngu, B. H. (2016). Academic Engagement: An Overview of Its Definitions, Dimensions, and Major Conceptualisations. International Education Studies, 9(12), 41-52.

Baños, J. H., Noah, J. P., \& Harada, C. N. (2019). Predictors of Student Engagement in Learning Communities. Journal of Medical Education and Curricular Development. https://doi.org/10.1177/ 2382120519840330

Bergdahl, N., Nouri, J., Fors, U., \& Knutsson, O. (2020). Engagement, disengagement and performance when learning with technologies in upper secondary school. Computers \& Education, 149, 103783.

Bond, M. (2020). Facilitating student engagement through the flipped classroom approach in K-12: A systematic review. Computers \& Education, 103819.

Bovermann, K., \& Bastiaens, T. (2020). Towards a motivational design? Connecting gamification user types and online learning activities. RPTEL, 15, 1. https://doi.org/10.1186/s41039-019-0121-4

Braun, V., \& Clarke, V. (2006). Using thematic analysis in psychology. Qualitative Research in Psychology, 3(2), 77-101.

Chen, B., Bastedo, K., \& Howard, W. (2018). Exploring Design Elements for Online STEM Courses: Active Learning. Engagement \& Assessment Design. Online Learning, 22(2), 59-75.

Cipriano, C., Barnes, T. N., Rivers, S. E., \& Brackett, M. (2019). Exploring changes in student engagement through the ruler approach: An examination of students at risk of academic failure. Journal of Education for Students Placed at Risk (JESPAR), 24(1), 1-19.

Cresswell, T. (2012). Geographic thought: A critical introduction. John Wiley \& Sons.

Czerkawski, B. \& Lyman, B. (2016). An Instructional Design Framework for Fostering Student Engagement in Online Learning Environments. Tech Trends 60, 532-539 (2016). https://doi.org/10.1007/ s11528-016-0110-Z

Czerniewicz, L., Trotter, H., \& Haupt, G. (2019). Online teaching in response to student protests and campus shutdowns: academics' perspectives. International Journal of Educational Technology in Higher Education, 16(1), 43.

Dixson, M. D. (2015). Measuring student engagement in the online course: The Online Student Engagement scale (OSE). Online Learning, 19(4), n4.

Dwivedi, A., Dwivedi, P., Bobek, S., \& Zabukovšek, S. S. (2019). Factors affecting students' engagement with online content in blended learning. Kybernetes.

Fraysier, K., Reschly, A., \& Appleton, J. (2020). Predicting Postsecondary Enrollment With Secondary Student Engagement Data. Journal of Psychoeducational Assessment, 38(7), 882-899. https://doi. org/10.1177/0734282920903168

Groccia, J. E. (2018). What is student engagement? New Directions for Teaching and Learning, 2018(154), 11-20. https://doi.org/10.1002/t1.20287

Halverson, L. R. (2016). Conceptualizing blended learning engagement. Doctoral Dissertation. Brigham Young University.

Hammill, J., Nguyen, T., \& Henderson, F. (2020). Student engagement: The impact of positive psychology interventions on students. Active Learning in Higher Education. https://doi.org/10.1177/14697 87420950589

He, H., Zheng, Q., Di, D., \& Dong, B. (2019). How learner support services affect student engagement in online learning environments. IEEE Access, 7, 49961-49973.

Keržič, D., Tomaževič, N., Aristovnik, A., \& Umek, L. (2019). Exploring critical factors of the perceived usefulness of blended learning for higher education students. PloS one, 14(11).

Khlaif, Z. N., \& Farid, S. (2018). Transforming learning for the smart learning paradigm: Lessons learned from the Palestinian initiative. Smart Learning Environments, 5(1), 1-21.

Khlaif, Z. N., \& Salha, S. (2020). The unanticipated educational challenges of developing countries in Covid-19 crisis: A brief report. Interdisciplinary Journal of Virtual Learning in Medical Sciences, 11(2), 130-134. 
Khlaif, Z. N., Salha, S., Affouneh, S., Rashed, H., \& ElKimishy, L. A. (2020). The Covid-19 epidemic: teachers' responses to school closure in developing countries. Technology, Pedagogy and Education, $1-15$.

Khlaif, Z. N., Salha, S., Fareed, S., \& Rashed, H. (2021). The hidden shadow of coronavirus on education in developing countries. Online Learning, 25(1), 269-285.

Lee, E., \& Hannafin, M. J. (2016). A design framework for enhancing engagement in student-centered learning: Own it, learn it, and share it. Educational technology research and development, 64(4), $707-734$

Li, X. (2018). Understanding eHealth literacy from a privacy perspective: eHealth literacy and digital privacy skills in American disadvantaged communities. American Behavioral Scientist, 62(10), 1431-1449. https://doi.org/10.1177/0002764218787019

Lie, A., Tamah, S. M., Gozali, I., Triwidayati, K. R., Utami, T. S. D., \& Jemadi, F. (2020). Secondary school language teachers' online learning engagement during the COVID-19 pandemic in Indonesia. Journal of Information Technology Education: Research, 19, 803-832

Lievens et al. (2019). Children's Rights and Digital Technologies. In International Human Rights of Children, International Human Rights, Kilkelly, T. Liefaard (eds.). https://doi.org/10.1007/978981-10-4184-6_16

Liu, J., \& Zhang, P. (2020). How to Initiate a Discussion Thread?: Exploring Factors Influencing Engagement Level of Online Deliberation. In: Sundqvist A., Berget G., Nolin J., Skjerdingstad K. (eds) Sustainable Digital Communities. iConference 2020. Lecture Notes in Computer Science, vol 12051. Springer, Cham.

Martin, F., \& Bolliger, D. U. (2018). Engagement matters: Student perceptions on the importance of engagement strategies in the online learning environment. Online Learning, 22(1), 205-222.

Martin, F., Wang, C., \& Sadaf, A. (2018). Student perception of helpfulness of facilitation strategies that enhance instructor presence, connectedness, engagement and learning in online courses. The Internet and Higher Education, 37, 52-65.

Nortvig, A. M., Petersen, A. K., \& Balle, S. H. (2018). A Literature Review of the Factors Influencing E-Learning and Blended Learning in Relation to Learning Outcome, Student Satisfaction and Engagement. Electronic Journal of e-Learning, 16(1), 46-55.

Oliveras-Ortiz, Y., Bouillion, D. E., \& Asbury, L. (2020). Learning Spaces Matter: Student Engagement in New Learning Environments. Journal of Education. https://doi.org/10.1177/0022057420 908062

Pellas, N. (2014). The influence of computer self-efficacy, metacognitive self-regulation and selfesteem on student engagement in online learning programs: Evidence from the virtual world of Second Life. Computers in Human Behavior, 35, 157-170.

Penuel, W. \& DiGiacomo, D. (2018). Organizing Learning Environments for Relational Equity in New Digital Media. In Second Handbook of Information Technology in Primary and Secondary Education, J. Voogt et al. (eds.), Springer International Handbooks of Education.

Resta, P. et al., (2018). Issues and Challenges Related to Digital Equity: An Overview. In Second Handbook of Information Technology in Primary and Secondary Education, J. Voogt et al. (eds.), Springer International Handbooks of Education. https://doi.org/10.1007/978-0-387-73315-9_44

Robertson, L. P., Leatham, H., Robertson, J., \& Muirhead, B. (2019). Digital privacy across borders: Canadian and American perspectives. In Emerging Trends in Cyber Ethics and Education (pp. 234-258). IGI Global. https://doi.org/10.4018/978-1-5225-5933-7.ch011

Tao et al. (2018). Perceived Online Learning Environment and Students' Learning Performance in Higher Education: Mediating Role of Student Engagement, in Cheung et al. (Eds.): ICTE 2018, CCIS 843, pp. 56-64, 2018. https://doi.org/10.1007/978-981-13-0008-06

Tofel-Grehl, C., Fields, D., Searle, K., Maahs-Fladung, C., Feldon, D., Gu, G., \& Sun, C. (2017). Electrifying engagement in middle school science class: Improving student interest through e-textiles. Journal of Science Education and Technology, 26(4), 406-417.

Topçu, M. S., Foulk, J. A., Sadler, T. D., Pitiporntapin, S., \& Atabey, N. (2018). The classroom observation protocol for socioscientific issue-based instruction: development and implementation of a new research tool. Research in Science \& Technological Education, 36(3), 302-323.

Traxler, J., Khaif, Z., Nevill, A., Affouneh, S., Salha, S., Zuhd, A., \& Trayek, F. (2019). Living under occupation: Palestinian teachers' experiences and their digital responses. Research in Learning Technology, 27. https://doi.org/10.25304/rlt.v27.2263 
Tualaulelei, E., Burke, K., Fanshawe, M., \& Cameron, C. (2021). Mapping pedagogical touchpoints: Exploring online student engagement and course design. Active Learning in Higher Education. https://doi.org/10.1177/1469787421990847

UNESCO (2020). COVID-19 Education Response. Retrieved from: https://en.unesco.org/covid19/ educationresponse/globalcoalition

United Nations. (2015). Sustainable development goals. Retrieved from: https://sustainabledevelopme nt.un.org

Wang, L. \& Sui, J. (2020). Correlation Analysis Between Emotional Engagement and Achievement of University Students in Online Learning Based on an Elective Course. In: Pan Z., Cheok A., Müller W., Zhang M. (eds) Transactions on Edutainment XVI. Lecture Notes in Computer Science, vol 11782. Springer, Berlin, Heidelberg.

Wheeler, L. B., Navy, S. L., Maeng, J. L., \& Whitworth, B. A. (2019). Development and validation of the classroom observation protocol for engineering design (COPED). Journal of Research in Science Teaching, 56(9), 1285-1305

Willems, J., Farley, H., \& Campbell, C. (2019). The increasing significance of digital equity in higher education. Australasian Journal of Educational Technology, 35(6), 1-8. https://doi.org/10.14742/ajet.5996

Wang, M. T., Fredricks, J., Ye, F., Hofkens, T., \& Linn, J. S. (2019). Conceptualization and assessment of adolescents' engagement and disengagement in school: A Multidimensional School Engagement Scale. European Journal of Psychological Assessment, 35(4), 592.

Wong, A., \& Chong, S. (2018). Modelling adult learners' online engagement behaviour: proxy measures and its application. J. Comput. Educ., 5, 463-479. https://doi.org/10.1007/s40692-018-0123-z

Yin, R. K. (2014). Case study research (5. (edition). SAGE.

Yuen, A. Park, J. Chen, L. \& Cheng, M. (2016). The significance of cultural capital and parental mediation for digital inequity. New Media \& Society, 20(2), 599-617. https://doi.org/10.1177/14614 44816667084

Zanjani, N. (2017). The important elements of LMS design that affect user engagement with e-learning tools within LMSs in the higher education sector. Australasian Journal of Educational Technology, 33(1).

Zydney, J. M., Warner, Z., \& Angelone, L. (2020). Learning through experience: Using design based research to redesign protocols for blended synchronous learning environments. Computers \& Education, 143, 103678.

Publisher's note Springer Nature remains neutral with regard to jurisdictional claims in published maps and institutional affiliations.

\section{Authors and Affiliations}

\section{Zuheir N. Khlaif $^{1}$ D $\cdot$ Soheil Salha ${ }^{1} \cdot$ Bochra Kouraichi $^{2}$}

Zuheir N. Khlaif

zkhlaif@najah.edu

Soheil Salha

ssalha@najah.edu

Bochra Kouraichi

Kouraichi.Bochra@stud.u-szeged.hu

1 An Najah National University, Nablus, Palestine

2 University of Szeged, Szeged, Hungary 